\title{
Optimization of a variable frequency drive pump working on a water tower
}

\author{
$N V$ Hruntovich $^{1, *}, A A$ Kapanski $^{1}, D$ Baczynski $^{2}, G V$ Vagapov $^{3}$ and $O V$ Fedorov $^{4}$ \\ ${ }^{1}$ Sukhoi State Technical University of Gomel, Prospect Octiabria, 48, 246746, Gomel, Republic of Belarus \\ ${ }^{2}$ Faculty of Electrical Engineering, Warsaw University of Technology, Pl. Politechniki 1,00-661, Warsaw, Poland \\ ${ }^{3}$ Kazan State Power Engineering University, str. Krasnoselskaya, 51, 420066, Kazan, Russia \\ ${ }^{4}$ Nizhny Novgorod State Technical University n. a. R.E. Alekseev, Minin St., 24, Nizhny Novgorod, 603950, Russia
}

\begin{abstract}
The development of the existing water supply system in towns and villages involves the use of frequency converters and specialized control algorithms that can maintain the pressure level established in the supply grid within certain limits. The implementation of the standard scheme includes the elimination of the water tower, which, on the one hand, reduces the cost of its maintenance. On the other hand, in emergency situations, the water tower can still supply water to the consumer, which increases the time of uninterrupted water supply during repairs. The article reveals a method of increasing the energy efficiency of transporting drinking water with the help of a water tower by eliminating the excessive pressure of the water rise when using frequency converters. Our research that involved more than 300 pumping stations, allowed to establish the average value of the excessive pressure of water rise, which reached $0.36 \mathrm{MPa}$. For the wells under study, optimization of the pump operation modes revealed the energy-saving potential of up to $52 \%$ due to excessive pressure reduction and up to $2.0 \%$ due to a decrease in starting power at the time of engine acceleration.
\end{abstract}

\section{Introduction}

In order to reduce the cost of water transport companies are implementing various measures aimed at increasing the efficiency of energy use. For the traditional water supply system, consisting of a group of pumping stations of the first and second lifting, water treatment plants and water supply systems, the main measures for energysaving include the replacement of outdated equipment with modern energy-efficient, reuse of wash water, reduction of leaks during transportation of fluid, optimization of pumping units and others [1]. The regulation of pumping unit operation modes for separate wells is performed by throttling, or by changing the rotational speed of the drive mechanisms, using frequency conversion devices with PID controllers tuned to maintain the specified pressure $[2,3,4,5]$. The use of frequency-regulated drives with the subsurface pump in small towns can exclude the water tower from the scheme of the water supply network and reduce the cost of its maintenance. In addition, the use of frequencyregulated drives helps eliminate water hammer when the pumps are running, to optimize the pressure in the network and to reduce the possibility of the pipe break [6].

In practical terms, the management staff of water utilities is not in a hurry to carry out the widespread modernization of the water supply network layout, since in emergency situations a water tower provides some water to the consumer. In addition, the operation of pumps is not recommended at a supply frequency below $30 \mathrm{~Hz}$, and therefore even in the absence of water consumption there will be a minimum level of energy costs, which in some cases will lead to inefficiency of the activities [7].

The purpose of the presented research is to develop a method for estimating the energy saving potential by frequency regulation of the operating modes of pumping units operating on a water tower by reducing the overpressure of the water rise and reducing the electric power losses during engine start.

\section{Experimental estimation of the deviation of the required pump head}

One of the ways to increase the energy efficiency of submersible pumps is to maintain an optimal pressure sufficient to lift water into the control tank and prevent exceeding the minimum level of water in the tank. To determine the required head, $\mathrm{m}$, created by the pump, we used actual data on the well depth and pump performance, casing diameter, static $H_{s t}$ and dynamic $H_{d}$ water level in the well, and geometric height of water rise: $H_{g}$ :

$$
H=\left(H_{g}-H_{d}\right)+\Delta H,
$$

\footnotetext{
*Corresponding author: gruntovich@tut.by
} 


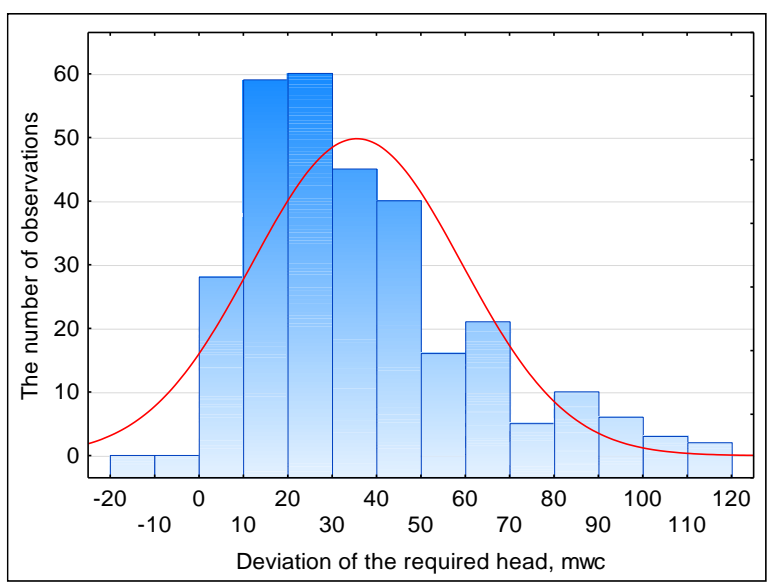

a)

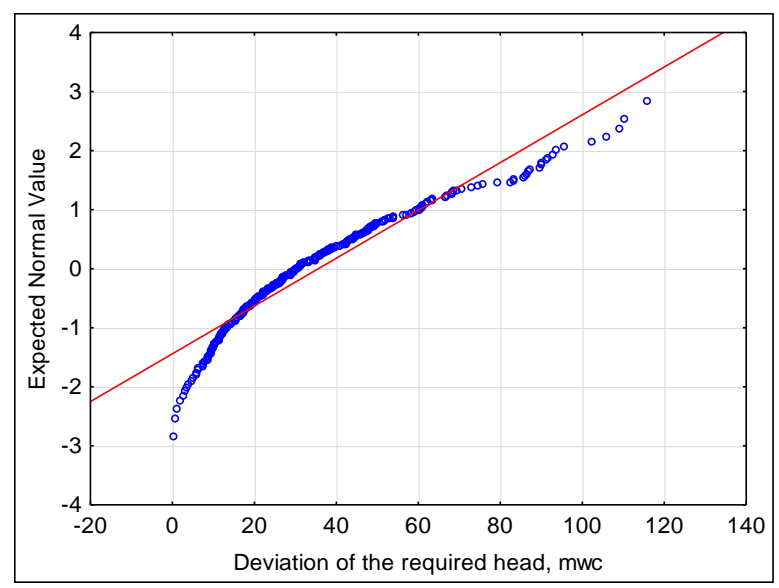

b)

Fig. 1. The histogram of the deviation of the actual water pressure from the required (a) and the normal-probability graph (b).

where $H_{g}$ - static head, which determines the difference between the geodetic levels of the supply and reception of fluid, $\mathrm{m} ; H_{d}-$ dynamic water level in the well, $\mathrm{m} ; \Delta H$ - hydraulic losses in the pressure pipeline, m.

The estimation of the degree of deviation of the required and actual pressure created by the pump is made for 7 water companies, covering more than 10 water intakes and 300 wells. Figure 1 shows the histogram of the distribution of excessive pressure of the raised water. Figure 1a shows that the pressure excess in some cases can reach $1.1 \mathrm{MPa}(115 \mathrm{~m})$, which determined the incorrectly chosen and significantly exceeded parameters of the pumps. The average value of the deviation of the pressure of pumping stations was $36.4 \mathrm{~m}$ or $0.36 \mathrm{MPa}$. Overpressure was determined by many factors (changes in the dynamic water level, lack of automation, wrong pump selection, etc.) therefore statistical tests rejected the hypothesis about the normal distribution of the overpressure factor (in Figure 1 (b) the values significantly deviated from the straight line).

Energy saving potential is realized due to complex automation of wells and regulation of their modes using frequency converters and specialized control algorithms. The pressure characteristics of the pump when changing the angular velocity of the drive unit is described by the quadratic parabola equation [6]:

$$
H(Q)=H_{f} \cdot\left(\omega / \omega_{\text {nom }}\right)^{2}-S_{f} Q^{2},
$$

where $H_{f}$ - fictitious pump head at zero flow, $\mathrm{m}$, in the absence of data for clean water $H_{f}=1,25 \cdot H_{n o m}$; $\omega, \omega_{\text {nom }}$ - variable and nominal angular velocity of the pump drive, $\mathrm{rad} / \mathrm{s} ; \quad S_{f}-$ hydraulic fictitious pump resistance, $\mathrm{m} \cdot\left(\mathrm{h} / \mathrm{m}^{3}\right)$.

The fictitious resistance of the pump can be determined from the formula (2) at the nominal flow, head and speed of the pump:

$$
S_{f}=\frac{H_{n o m}-H_{f}}{Q_{\text {nom }}^{2}}=\frac{H_{n o m}-1,25 \cdot H_{n o m}}{Q_{n o m}^{2}},
$$

where $Q_{\text {nom }}$ - nominal pump flow, $\mathrm{m}^{3} / \mathrm{h}$.

The pressure characteristic of the pipeline network is also described by a quadratic parabola equation using the formula [7]:

$$
H(Q)=H_{g}+S_{t} Q^{2}
$$

where $S_{f}-$ hydraulic resistance of the pipeline network, $\mathrm{m} \cdot\left(\mathrm{h} / \mathrm{m}^{3}\right)$ :

$$
S_{t}=\frac{H_{g}-H_{n o m}}{Q_{n o m}^{2}} .
$$

At the intersection of the pressure characteristics of the pump and the pipe network, a steady state is formed, which determines the actual performance and pressure of the pump unit, and solving the system of equations (2) and (4) allows the hydraulic characteristics to be related to the angular velocity of the electric drive. The actual roots of the equation determine the pump work area:

$$
\begin{aligned}
& H(\omega)=\frac{S_{f} H_{g}+\left(\omega / \omega_{\text {nom }}\right)^{2} S_{t} H_{f}}{S_{f}+S_{t}}, \\
& Q(\omega)=\sqrt{-\frac{H_{g}-\left(\omega / \omega_{\text {nom }}\right)^{2} H_{f}}{S_{f}+S_{t}}} .
\end{aligned}
$$

The efficiency of the engine $\mu_{\text {m.nom }}$ and the frequency converter throughout $\mu_{V F D}$ the entire range of angular velocity changes remains close to the nominal [8], and the hydraulic efficiency of the pump varies in accordance with the Moody formula [8]: 


$$
\mu_{p}(\omega)=1-\frac{1-\mu_{p . n o m}}{\left(\omega / \omega_{n o m}\right)^{0,36}} .
$$

where $\mu_{\text {p.nom }}-$ nominal hydraulic efficiency of the pump.

\section{Energy efficiency to reduce excessive pressure during lifting water}

Let's consider the case of the pump on the water tower with a nominal pressure $H_{\text {nom }}=100 \mathrm{~m}$, performance $Q_{\text {nom }}$ $=25 \mathrm{~m}^{3} / \mathrm{h}$, efficiency $\mu_{\text {p.nom }}=0.742$ and rotational speed $n_{\text {nom }}=2900 \mathrm{rpm} \quad\left(\omega_{\text {nom }}=304 \mathrm{rad} / \mathrm{s}\right)$. Nominal parameters of the electric motor: power $P_{n o m}=11 \mathrm{~kW}$; efficiency $\mu_{\text {m.nom }}=0.822$; overload capacity $\lambda=M_{\text {max }} / M_{\text {nom }}=2.2$; moment of inertia $J=0.11 \mathrm{~kg} / \mathrm{m}^{2}$. The volume of the water tower $-V=$ $30 \mathrm{~m}^{3}$, annual water $-Q_{\text {year }}=7634 \mathrm{~m}^{3}$, maximum hourly water consumption $Q_{\max }=2.0 \mathrm{~m}^{3}$.

As a result of the hydraulic calculation, the required water head $H_{r}=65 \mathrm{~m}$ was determined in accordance with (1), which will reduce the excessive pressure of the water rising into the water tower: $\Delta h=\Delta H_{1}-\Delta H_{2}$. An explanatory diagram of the water supply network is shown in Figure 2.

Reducing the head (from point 1 to 2 in the diagram of Figure 2), by changing the rotational speed of the pump impeller, in accordance with the pressure characteristic (2) will reduce the head from $Q_{n o m}$ to $Q_{r}$, and therefore, it is necessary to comply with the provision specified performance at hours of maximum water consumption:

$$
Q_{r} \geq Q_{\max }
$$

The angular velocity of the engine can be obtained by solving equation (6) with a known head or pump feed:

$$
\omega_{r}=\frac{\omega_{\text {nom }} \sqrt{S_{t} H_{f}\left(S_{t} H_{r}-S_{f} H_{g}+S_{f} H_{r}\right)}}{S_{t} H_{f}} .
$$

The limiting angular velocity, which determines the stable operation of the pump, is found as a result of solving equation (6) for $Q(\omega)[8,9,10]$ :

$$
\omega_{b}=\omega_{\text {nom }} \sqrt{H_{g} / H_{f}} .
$$

Thus, the observance of the frequency control conditions must proceed from the possible control ranges:

$$
\omega_{r} \geq \omega_{b} \text { and } \omega_{r} \geq \frac{2 \pi f_{\min }(1-s)}{p},
$$

where $f_{\text {min }}$ - permissible minimum frequency of power during pump operation, $\mathrm{Hz}$; $s, p-$ motor slip and the number of pole pairs.

The actual power, $\mathrm{kW}$, spent on the rise of water at a known angular velocity of the pump, is determined by the formula [8]:

Fig. 2. Regulation of the mode of operation of the pump by reducing the engine speed. 


$$
P(\omega)=\frac{\rho \cdot Q(\omega) \cdot H(\omega)}{3600 \cdot 102 \cdot \mu_{p}(\omega) \cdot \mu_{m . n o m} \cdot \mu_{V F D}} .
$$

Reducing the annual cost of electrical energy by reducing the overpressure of rising water at a known volume of water consumption can be determined through the value of the specific power consumption of the pump at a known performance:

$$
\begin{aligned}
& \Delta W=\left(\frac{P\left(\omega_{\text {nom }}\right)}{Q_{\text {nom }}}-\frac{P\left(\omega_{r}\right)}{Q_{r}}\right) Q_{\text {year }}= \\
& =\left(w_{d}\left(\omega_{\text {nom }}\right)-w_{d}\left(\omega_{r}\right)\right) Q_{\text {year }},
\end{aligned}
$$

where $w_{d}$ - specific power of fluid transportation, $\mathrm{kW} \cdot \mathrm{h} / \mathrm{m}^{3}$.

Figure 3 shows the change in the specific energy consumption while reducing the angular velocity of rotation of the pump. Studies have been conducted to establish the energy-saving potential by reducing the pressure of rising water from 2 to $52 \%$ of the total cost of electrical energy, respectively.

\section{$P_{d}, \mathrm{kWh} / \mathrm{m}^{3}$}

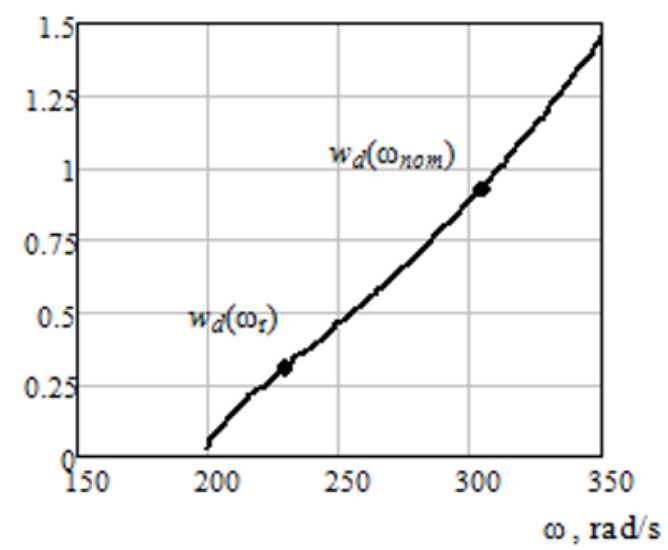

Fig. 3. The change in the specific consumption of electricity when changing the angular velocity of the pump.

\section{Energy efficiency to reduce the starting power of the electric drive}

The short-term nature of water consumption by rural customers causes the pump to be turned on repeatedly throughout the year. Depending on the volume of the tank, the number of inclusions can be determined by the formula:

$$
n_{s t}=Q_{\text {year }} / V_{t}
$$

The increase in power demand during the engine acceleration can reach sevenfold values of steady state. The use of soft starters or variable frequency drives restricts excessive torque and reduces inefficient use of electrical energy $[11,12]$. To determine the energy saving potential, we turn to the simplified mechanical characteristic of the engine, which is determined in accordance with the Kloss formula, given through the angular velocity [13]:

$$
M_{e . m}(\omega)=\frac{2 M_{\max }}{\left(1-\omega / \omega_{s}\right) / s_{k}+s_{c} /\left(1-\omega / \omega_{k}\right)},
$$

where $M_{\max }-$ maximum engine torque, $\mathrm{N} \cdot \mathrm{m} ; \omega_{s}$ synchronous angular velocity, $\mathrm{rad} / \mathrm{s} ; s_{k}$ - critical slip.

The load torque $M_{p . u}(\omega)$ in the area of stable operation of the pump unit is determined by dividing the hydraulic power of the pump (12) by the angular velocity $\omega$. When the speed drops below $\omega_{b}$, a nonoperational mode of pump operation with a moment $M_{p . d}(\omega)$ is formed, in which the friction torque $M_{t}$ and the idle speed of the mechanism $M_{0}$ [14]. Thus, the total load torque of the mechanism, $\mathrm{N} \cdot \mathrm{m}$, is represented by two components $[8,15]$ :

$$
M_{p}(\omega)=\left\{\begin{array}{l}
M_{p . u}(\omega)=\frac{\rho \cdot Q(\omega) \cdot H(\omega)}{3600 \cdot 102 \cdot \mu_{p}(\omega) \cdot \omega} 10^{3} \\
\text { for } \omega \geq \omega_{b} \\
M_{p . d}(\omega)=\left(M_{0}-M_{t}\right)\left(\omega / \omega_{\text {nom }}\right)^{2}+M_{t} \\
\text { for } \omega<\omega_{b} .
\end{array}\right.
$$

To simplify the mathematical description of the pump load torque in the estimated calculations of the energy saving potential due to the smooth start-up, a transition from a piecewise continuous function to a power law is proposed:

$$
M_{p . a}(\omega)=M_{p . u}\left(\omega_{\text {nom }}\right) \cdot\left(\omega / \omega_{\text {nom }}\right)^{k}
$$

where $k$ - coefficient taking into account the steepness of the characteristics of the moment:

$$
k=\frac{\ln \left(M_{p . u}\left(\omega_{\text {nom }}\right) / M_{p . u}\left(\omega_{\min }\right)\right)}{\ln \left(\omega_{\text {nom }} / \omega_{\min }\right)},
$$

where $\omega_{\min }-$ minimum angular velocity, determined with a known minimum performance $Q_{\min }$ by the formula [7]:

$\omega_{\text {min }}=\omega_{\text {nom }} \sqrt{H_{g} / H_{f}+\left(1-H_{g} / H_{f}\right) \cdot\left(Q_{\min } / Q_{\text {nom }}\right)}$.

Figure 4 shows the mechanical characteristics of the engine and pump, constructed from equations (15), (16) and (17). 


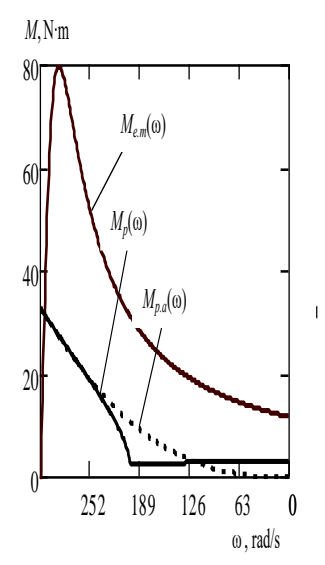

Figure 4. Mechanical characteristics of the engine and

pump

Fig. 4. Mechanical characteristics of the engine and pump.

To determine the duration of the start-up, we used the equation of motion of the rotor of the induction motor, reduced to the Cauchy form, taking into account the transition from the moment to the power of the engine $P_{e . m}(\omega)$ and pump $P_{p . a}(\omega)$ :

$$
\frac{d \omega}{d t}=P_{e . m}(\omega)-P_{p . a}(\omega)=\Delta P(\omega) .
$$

Figure 5 shows the change in the angular velocity of the pump motor during acceleration, as well as the change in unbalance of mechanical and electrical power, which determines the potential of energy efficiency during frequency regulation.

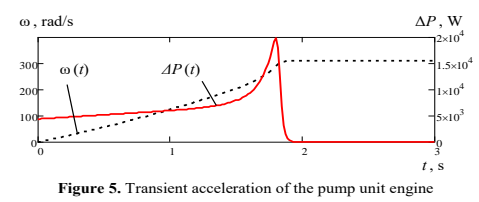

Fig. 5. Transient acceleration of the pump unit engine.

With a known dependence of $\Delta P(t)$, the time of the transition process $t_{p}$ and the number of pump starts during the year, the potential for energy saving is determined by:

$$
\Delta W_{s t}=n_{s t} \int_{0}^{t_{p}} \Delta P(t) .
$$

For the considered pump with inertia $J=0.11 \mathrm{~kg} / \mathrm{m}^{2}$, the average start-up time was $t_{p} \approx 2 \mathrm{~s}$, and the decrease in power consumption due to the smooth start-up decreased slightly $\approx 0,264 \mathrm{~kW} \cdot \mathrm{h}$. For the wells studied, the soft start efficiency did not exceed $2.0 \%$ of the total power consumption.

\section{Conclusions}

The energy saving potential realized due to the complex automation of the wells under study and regulation of their modes using frequency converters and specialized control algorithms allows eliminating excessive pressure and reducing electricity costs at the moment of pump engine acceleration.

For the wells under study, optimization of pumping unit operation modes made it possible to realize energy saving potential up to $52 \%$ due to reduction of excess pressure and up to $2.0 \%$ due to reduction of starting power at the moment of engine acceleration

\section{References}

1. N. Makisha, T. Kazimirova, Principles of energy saving in water supply and sewage systems, In MATEC Web of Conferences, 144, 04013 (2018)

2. S.Bezerra, S. Silva, H. Gomes, M. Salvino, Energy savings in pumping systems: application of fuzzy system, Science and Engineering Journal, 24(1), 71-78 (2015)

3. S. Dabadgaonkar, A.K. Sen, Controlling of Pump Onboard Ship using Variable Frequency Drive with Three-phase Inverter and Three Phase Induction Motor, MIT International Journal of Electrical and Instrumentation Engineering, 1(2) (2011)

4. T. Pelli, H.U. Hitz, Energy indicators and savings in water supply, Journal-American Water Works Association, 92(6), 55-62 (2000)

5. A.A. Kapansky, Energy Efficiency of the Technological Systems of Water Supply and Drainage and Methods of Its Evaluation, Izv. higher studies. institutions and energy. about the CIS, 5, 436-451 (2016)

6. Yu. Korchevskaya, G. Gorelkina, Possibilities of regulating uninterrupted water supply to the network of small settlements, Bulletin of Altai State Agrarian University, 1(135), 138-142 (2016)

7. P. Hristo, Research of the opportunity of optimization of pump installation, Electrotechnic and Computer Systems, 15(91), 110-113 (2014)

8. V. Fashchilenko, Regulated electric drive of pumping and fan installations of mining enterprises, 260 (2017)

9. O.V. Fedorov, Estimates of the effectiveness of variable frequency drives, 144 (2011)

10. E.I. Gracheva, O.V. Naumov, R.R. Sadykov, Processing of statistical information in order to identify the laws of changes in the reliability parameters of equipment for workshop networks, News of Higher Educational Institutions of the Black Earth Region, 2, 34-43 (2016)

11. E.I. Gracheva, Estimation of electric power losses in low-voltage switching devices, News of higher educational institutions. Energy problems, 74-81 (2009) 
12. A.A. Shpiganovich, K.A. Pushnitsa, E.V. Churkina, O.V. Fedorov, Features of the operation of power supply systems of ferrous metallurgy enterprises, Ferrous metals, 5, 56-61 (2017)

13. V.I. Klyuchev, Electric drive theory, 704 (2001)

14. B.S. Leznov, S.V. Vorobyev, Centrifugal pump operation with variable rotational speed, Water supply and sanitary equipment, 9, 48-56 (2012)

15. E.G. Andreeva, A.Y. Kovalev, Decomposition of the mechanical characteristics of an asynchronous electric motor according to the Kloss formula, Omsk Scientific Bulletin, 3 (83), 191-193 (2009) 